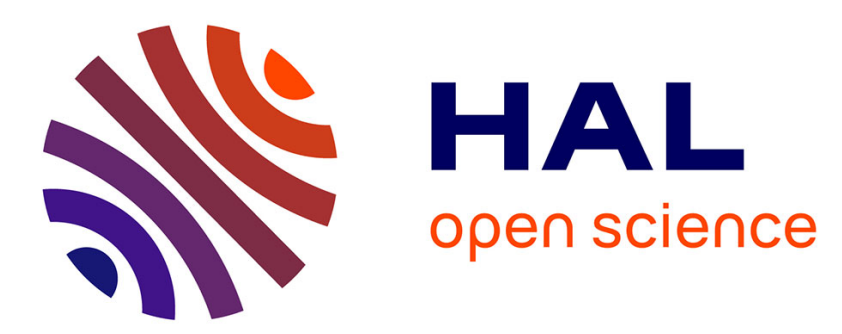

\title{
Natural convection of CNT water-based nanofluids in a differentially heated square cavity
}

Patrice Estellé, Omid Mahian, Thierry F Maré, Hakan F Öztop

\section{To cite this version:}

Patrice Estellé, Omid Mahian, Thierry F Maré, Hakan F Öztop. Natural convection of CNT waterbased nanofluids in a differentially heated square cavity. Journal of Thermal Analysis and Calorimetry, 2017, 128 (3), pp.1765-1770. 10.1007/s10973-017-6102-1 . hal-01445989

HAL Id: hal-01445989

https://hal-univ-rennes1.archives-ouvertes.fr/hal-01445989

Submitted on 25 Jan 2017

HAL is a multi-disciplinary open access archive for the deposit and dissemination of scientific research documents, whether they are published or not. The documents may come from teaching and research institutions in France or abroad, or from public or private research centers.
L'archive ouverte pluridisciplinaire HAL, est destinée au dépôt et à la diffusion de documents scientifiques de niveau recherche, publiés ou non, émanant des établissements d'enseignement et de recherche français ou étrangers, des laboratoires publics ou privés. 


\title{
Natural convection of CNT water based nanofluids in a differentially heated square cavity
}

\author{
Patrice Estellé $^{1, *}$, Omid Mahian ${ }^{2}$, Thierry Maré ${ }^{1}$, Hakan F. Öztop ${ }^{3}$ \\ ${ }^{1}$ LGCGM, Equipe Matériaux et Thermo-Rhéologie, Université Rennes 1, Rennes, France \\ ${ }^{2}$ Young Researchers and Elite Club, Mashhad Branch, Islamic Azad University, Mashhad, \\ Iran \\ ${ }^{3}$ Department of Mechanical Engineering, Technology Faculty, Firat University, Elazig, \\ Turkey \\ * Author to whom correspondence should be addressed. \\ Electronic mail: patrice.estelle@univ-rennes1.fr \\ IUT de Rennes, 3 rue du Clos Courtel, BP 90422, \\ 35704 Rennes Cedex 7, France \\ Tel: $+33(0) 23234200$ \\ Fax: +33(0) 223234051
}

\begin{abstract}
The present paper deals with the prediction of average Nusselt number in a differentially heated square cavity filled with Newtonian and non-Newtonian CNT nanofluids. Based on thermophysical properties which were experimentally evaluated, available correlations are used for estimating the Nusselt number and heat transfer coefficient of natural convection of CNT nanofluids with volume fractions in a range of 0.0055 to $0.418 \%$. The effects of surfactant, average temperature of nanofluids within the cavity, driving temperature of cavity walls on Nusselt number are investigated and discussed. A peculiar attention is devoted to the non-Newtonian nature of CNT nanofluids in the analysis. It is found in particular that Nusselt number of nanofluids is lowered by nanoparticle content increase related to Non-Newtonian behaviour of nanofluids and temperature increase.
\end{abstract}




\section{Keywords}

CNT nanofluid, natural convection, cavity, volume fraction influence, Non-Newtonian effect

\section{Nomenclature}

$\rho$ density, $\mathrm{kg} \mathrm{m}^{-3}$

$\mathrm{k}$ thermal conductivity, $\mathrm{W} \mathrm{m}^{-1} \mathrm{~K}^{-1}$

$\mu$ viscosity, $\mathrm{Pa} \mathrm{s}$

$\dot{\gamma}$ shear rate, $\mathrm{s}^{-1}$

$\tau$ shear stress, $\mathrm{Pa}$

$\eta$ consistency $\left(\mathrm{Pa} \mathrm{s}^{\mathrm{n}}\right)$

n flow index behavior (-)

$\mathrm{C}_{\mathrm{p}}$ specific heat, $\mathrm{J} \mathrm{kg}^{-1} \mathrm{~K}^{-1}$

$\beta$ thermal expansion coefficient $\left(\mathrm{K}^{-1}\right)$

$\phi$ nanoparticle volume fraction

$\mathrm{Nu}$ Nusselt number

Ra Rayleigh number

Pr Prandtl number

L Length and height of the enclosure, $m$

g gravity, $\mathrm{m} \mathrm{s}^{-2}$

CNT carbon nanotubes

SDBS sodium dodecyl benzene sulfonate

\section{Subscripts}

bf base fluid

nf nanofluid

np nanoparticle

rel relative

c cold

h hot

a average 


\section{Introduction}

Due to relevance in many engineering applications, heat transfer from natural convection in enclosures was largely investigated in literature. The last few years, studies mainly concern the use of nanofluids instead of pure conventional fluids like water, oil and ethylene glycol based fluids. In this field, the main results were reviewed in [1,2] considering a large variety of configurations and enclosures and nanofluids nature as well. This evidences the potential of nanofluids as enhanced heat transfer fluids, enhancement being mostly dependent to nature of nanoparticles [3]. It appears also that previous studies are mainly based on numerical works.

Before performing a comprehensive numerical work to compute isotherm and streamline patterns within an enclosure, it could be first envisaged to use existing Nusselt number correlations for natural convection prediction, as recently suggested and demonstrated in [4]. This only requires the use of well selected theoretical models or preliminary evaluation of thermophysical properties of nanofluids. Some studies have been performed to show the uncertainties of theoretical models used evidencing the role of well representative correlations for heat transfer evaluation under natural convection [5-7].

As already mentioned, a lot of studies have been conducted on various types of metallic and non-metallic oxide nanoparticles. However, whereas CNTs possess very high intrinsic thermal conductivity, there is no more report on natural convection of CNT nanofluids. Many works have been performed to evaluate the thermal conductivity of CNT nanofluids, as nicely reviewed in [8]. This is also shown in recent works $[9,10]$. However, there is still no reliable and universal model for thermal conductivity enhancement of CNT nanofluids, as shown in recent work [11]. In addition, reliable viscosity model for CNT nanofluids was only developed for high shear rate $[12,13]$.

Natural convection of CNT nanofluids was experimentally investigated by Li et al. [14] with a closed rectangular vessel heated from the lower surface, the upper one being cooled by room temperature. It was shown that buoyancy induced convection and heat transfer capacity were reduced because of non-Newtonian nature of nanofluids compared to pure water. One can also mention a recent numerical study reported in [15] considering a trapezoidal configuration filled with EG-water-CNT nanofluids with a vertical driven 
temperature difference and insulated side walls. The influence of inclination angles $\left(15-75^{\circ}\right)$, Rayleigh number $\left(10^{3}-10^{6}\right)$ and nanoparticles content $(0.15-4.5 \%$ in vol.) were investigated. It was reported that buoyancy induced convection produces for Rayleigh numbers higher than $10^{5}$. In this range, average Nusselt number was found to decrease with increasing inclination angle with all tested nanoparticle contents. Higher Nusselt number was obtained at $30^{\circ}, 0.15 \%$ in volume fraction and $\mathrm{Ra}=10^{6}$.

This purpose of this note is to estimate the natural convection of CNT water based nanofluid stabilized with SDBS in a square enclosure from temperature dependant thermophysical properties previously measured. In this way, the available correlations for Nusselt number for natural convection of fluids in a square enclosure were used and the effects of non-Newtonian nature of nanofluids, following the volume fraction in nanotubes, were considered. Nanofluid temperature, nanoparticle volume fraction, temperature difference of heated vertical walls on Nusselt number were also presented and discussed.

\section{Thermophysical properties of nanofluids}

The nanofluids considered here have been previously investigated in $[11,12,16,17]$. They consist of MWCNTs (carbon purity 90\%; nanotubes density $1800 \mathrm{~kg} / \mathrm{m}^{3}$ ) dispersed by using ultrasonic processing in de-ionized water and stabilized by sodium dodecyl benzene sulfonate (SDBS) as surfactant. The average size of the nanotubes is $1.5 \mu \mathrm{m}$ in length and 9.2 $\mathrm{nm}$ in diameter, respectively. Different nanofluid samples were prepared following the procedure described in Ref. [12] with volume fraction varying from $0.418 \%$ to $0.0055 \%$. The rheological properties of these nanofluids, and corresponding base fluids, were previously measured in Ref. [12] for temperature range between 20 and $40^{\circ} \mathrm{C}$. For these temperatures, a Newtonian behavior was reported for base fluids with a decrease of viscosity values with surfactant content and temperature decrease, as seen in Table 1. It should be noted that surfactant content is related to nanotubes loadings, with a constant weight ratio of 2 . Table 2 indicates the behavior of nanofluids (Newtonian or non-Newtonian) depends on volume fraction and temperature of suspensions. The rheological behaviors can be described by the following relationships between shear stress $\tau$ and shear rate $\dot{\gamma}$.

For Newtonian fluid, 


$$
\tau=\mu \dot{\gamma}
$$

With $\mu$ the viscosity.

For non-Newtonian fluid,

$$
\tau=\eta \dot{\gamma}^{n}
$$

where $\eta$ is the consistency and $n$ is the flow index behavior.

By means of curve fitting of previous experimental results, the rheological parameters of equations (1) and (2), namely viscosity, consistency and flow index were obtained as reported in Tables 1 and 2 as a function of surfactant content, temperatures, and nanoparticle loadings.

The thermal conductivity of nanofluids and base fluids considered here was also previously measured in Ref. [11], showing that thermal conductivity of nanofluids enhances with both volume fraction and temperature. As shown in Ref. [11], the lack of reliability of existing thermal conductivity models for CNT nanofluids with our results evidences the need to use experimental data rather than theoretical correlations.

The density of nanofluids was also measured in a recent study [17]. These data were here used and additional measurements were also performed following the same procedure to cover the entire range of volume fraction presently investigated.

In absence of experimental data, the heat capacity of the nanofluids was calculated from the following theoretical correlation [18], neglecting the heat capacity of surfactant [17].

$$
C_{p, n f}=\frac{\phi\left(\rho C_{p}\right)_{n p}+(1-\phi)\left(\rho C_{p}\right)_{b f}}{\phi \rho_{n p}+(1-\phi) \rho_{b f}}
$$

In the same way, the volumetric thermal expansion coefficient $\beta$ of nanofluids was analytically evaluated from the following equation [19] as

$$
\beta_{n f}=\frac{\phi(\rho \beta)_{n p}+(1-\phi)(\rho \beta)_{b f}}{\phi \rho_{n p}+(1-\phi) \rho_{b f}}
$$


Here, within the range of tested temperatures the thermal expansion coefficient for the CNT nanotubes was taken to $2 \times 10^{-5} \mathrm{~K}^{-1}$ from Ref. [20]. It should be noted that the effect of temperature on heat capacity of water was obviously considered. Equation (3) induces the decrease of volumetric thermal expansion coefficient of nanofluid with increasing volume fraction. The thermal expansion coefficient of nanofluids depends also on temperature and decreases with temperature rise.

\section{Problem description}

A differentially heated square cavity filled with CNT nanofluid is considered in this study. The schematic of the problem is shown in Fig. 1. On the right side of the enclosure, the temperature is considered as hot and denoted $\mathrm{T}_{\mathrm{h}}$. On the left side the temperature is cold and denoted $T_{c}$. The mean temperature of the hot and cold walls corresponds to the nanofluid temperature. Since the nanofluid thermophysical properties are temperature dependent for the investigated temperatures 20,30 and $40^{\circ} \mathrm{C}$, this implies that non-dimensional numbers also vary with temperature.

For a square cavity with differentially heated vertical walls filled with Newtonian fluid, the correlation for average Nusselt number proposed by Turan et al. [21], expressed by equation (5), can be used. This equation appears as an improvement of the BerkovskiePolevikov equation [22] in particular for high Prandtl numbers.

$$
N u=0.162 R a^{0.293}\left(\frac{\mathrm{Pr}}{1+\operatorname{Pr}}\right)^{0.091}
$$

The Rayleigh number Ra is defined as

$$
R a=\frac{g \beta \rho^{2} C_{p} \Delta T L^{3}}{\mu k}
$$

and, the Prandtl number Pr writes as 


$$
\operatorname{Pr}=\frac{\mu C_{p}}{k}
$$

In the case of non-Newtonian fluids, the average Nusselt number can be expressed in terms of algebraic function of $\mathrm{Ra}, \mathrm{Pr}$, and flow index behavior " $\mathrm{n}$ " [21] as

$$
N u=0.162 R a^{0.043} \frac{\operatorname{Pr}^{0.341}}{(1+\operatorname{Pr})^{0.091}}\left(\frac{R a^{2-n}}{\operatorname{Pr}^{n}}\right)^{\frac{1}{2(n+1)}} e^{b(n-1)}
$$

where $\mathrm{b}$ writes as follows

$$
b=c_{1} R a^{c_{2}} \operatorname{Pr}^{c_{3}}
$$

in the above, $c_{1}, c_{2}$ and $c_{3}$ are given by the following relationships for $\mathrm{n} \leq 1$

$$
\mathrm{c}_{1}=1.343 ; \mathrm{c}_{2}=0.065 ; \mathrm{c}_{3}=0.036
$$

also, in this case $\mathrm{Ra}$ and $\mathrm{Pr}$ numbers are respectively expressed as

$$
\begin{aligned}
& R a=\frac{g \beta \rho^{n+1} C_{p}{ }^{n} \Delta T L^{2 n+1}}{\eta k^{n}} \\
& \operatorname{Pr}=\frac{\eta}{\rho}\left(\frac{k}{\rho C_{p}}\right)^{n-2} L^{2-2 n}
\end{aligned}
$$

It should be noted that equations (8), (11) and (12) reduce to equations (5), (6) and (7), respectively, when $\mathrm{n}$ is taken to 1 , i.e. for Newtonian fluids. The correlations given by equations (8) to (12) are for $10^{4} \leq \mathrm{Ra} \leq 10^{6}$ and $0.6<\mathrm{n} \leq 1$ [21].

A square cell dimension of $25 \times 25 \mathrm{~mm}^{2}$ was here considered. In addition, the $\Delta \mathrm{T}=\mathrm{T}_{\mathrm{h}}-$ $T_{c}$ values were tested and selected to check previous conditions related to Ra and Pr numbers 
for both base fluids and nanofluids. In addition, as previous equations were based on a Boussinesq approximation, the driving temperature difference should remain small for this to be valid.

Consequently, $\Delta \mathrm{T}=\mathrm{T}_{\mathrm{h}}-\mathrm{T}_{\mathrm{c}}$ starts from 0.1 up to 4,2 and 1.5 for nanofluids average temperature of 20,30 and $40^{\circ} \mathrm{C}$ respectively. This also implies that Ra number of nanofluids cannot be obtained for some nanoparticle volume fractions following the difference in wall temperature. As shown in Table 2, flow index $\mathrm{n}$ is well within the validity domain of equations whatever the nanoparticle loadings and average temperature considered.

\section{Results and discussion}

The results are presented in two subsections. First, the variation of Nusselt number for base fluids is presented. Next, the effects of various parameters such as temperature and concentration are investigated on the magnitude of Nusselt number of nanofluids.

\subsection{Base fluids}

Figure 2 shows the variations of Nusselt number for deionized water and the mixture of water and SDBS as surfactant with different volume fractions where the temperature difference between hot and cold walls and the average temperature of base fluids change. First, it is observed from Fig. 2 that, at both fixed average temperature and temperature difference between hot and cold walls, Nusselt numbers of base fluids are quite constant. It should be recalled that for the range of surfactant content, viscosity of base fluids increase with surfactant content (see Table 1) while, inversely, thermal conductivity decreases $[9,10]$. Based on the use of equation (6), this evidences a weak dependence of Nusselt number on Prandtl number. Obviously, when surfactant content is fixed, Fig. 2 shows the increase of Nusselt numbers of base fluids with respect to the increase in temperature difference between hot and cold walls. This is observed for all average temperatures of base fluids. Finally, with a fixed value of $0.1^{\circ} \mathrm{C}$ for temperature difference between hot and cold walls, one can see in Fig. 2 that Nusselt numbers of base fluids increase with average temperature of base fluids. Similar trends were obtained when the temperature difference between hot and cold walls is changed (not reported here).

\subsection{Nanofluids}


The effect of nanoparticle content, average temperature of nanofluids and driving temperature difference between hot and cold walls on Nusselt number of nanofluids are pointed out in Fig. 3. First, Fig. 3 shows that Nusselt number of nanofluids increases with the driving temperature between vertical walls. Moreover, it is also observed that Nusselt number decreases when the average temperature of nanofluids is increased. This is particularly true when the temperature rises from 30 to $40^{\circ} \mathrm{C}$. In addition, Nusselt number is lowered by nanoparticle content increase. This shows the competition between thermal conductivity which increases with both temperature and nanoparticle content while viscosity decreases with temperature but largely increases with nanoparticle volume fraction. So, this balance drives the heat transfer enhancement in the enclosure from natural convection.

So, it is evidenced that heat transfer of CNT nanofluids from natural convection in enclosure is rather sensitive to their rheological properties and in particular their nonNewtonian nature for volume fraction higher than $0.055 \%$. Actually, shear-thinning behavior penalizes the onset and sustaining of natural convection in particular for low temperature difference between vertical walls.

Finally, the influence of nanoparticle content, average temperature of nanofluids and driving temperature difference between hot and cold walls on relative Nusselt number, defined as the ratio of Nusselt number of nanofluids to the one of base fluids is displayed in Fig. 4. Similar trends that the ones reported in figure 3 are observed as Nusselt number of base fluid is quite constant with surfactant increase which is related to nanoparticle increase also. Consequently, the best enhancement in heat transfer from natural convection due to presence of nanoparticles is achieved at lower temperature and within the range of $0.0055 \%$ to $0.055 \%$ in volume fraction with a weak influence of temperature difference between hot and cold walls.

\section{Conclusions}

The prediction of natural convection of CNT-water based nanofluids within a square enclosure partially heated was performed. The Nusselt number in the enclosure was evaluated from available correlations depending on thermophysical properties of nanofluids. In contrast to main previous investigations, where theoretical predictions for thermal conductivity and viscosity were used, experimental data were here considered, avoiding uncertainties related to 
unappropriated models. Moreover, the effect of average temperature and volume fraction of nanofluids, driving temperature between hot and cold walls and role of surfactant was investigated. The influence of non-Newtonian nature of some nanofluids depending on nanoparticle content and temperature was also discussed.

The results mainly evidence that Nusselt number of nanofluids is lowered by nanoparticle content increase related to Non-Newtonian behaviour of nanofluids and temperature increase, inversely to thermal conductivity. An optimum in natural convection due to presence of nanoparticles was reported at both low temperature and nanoparticle content.

\section{References}

1. Haddad Z, Öztop HF, Abu-Nada E, Mataoui A. A review on natural convective heat transfer of nanofluids. Renew Sust Energy Rev. 2012;16:5363-5378.

2. Öztop HF, Estellé P, Yan W-M, Al-Salem K, Orfi J, Mahian O. A brief review of natural convection in enclosures under localized heating with and without nanofluids. Int Com Heat Mass Transfer. 2015;60:37-44.

3. Öztop HF, Abu-Nada E. Numerical study of natural convection in partially heated rectangular enclosures filled with nanofluids. Int J Heat Fluid Flow. 2008;29:1326-1336.

4. Abouali O, Ahmadi G. Computer simulations of natural convection of single phase nanofluids in simple enclosures: A critical review. Appl Thermal Eng. 2012;36:1-13.

5. Ho CJ, Chen MW, Li ZW. Numerical simulation of natural convection of nanofluid in square enclosure: effects due to uncertainties of viscosity and thermal conductivity. Int J Heat Mass Transfer. 2008;51:4506-4516.

6. Abouali $\mathrm{O}$, Falahat Pisheh A. Numerical investigation of natural convection of $\mathrm{Al}_{2} \mathrm{O}_{3}$ nanofluid in vertical annuli. Heat Mass Transfer. 2009;46:15-23.

7. Hwang KS, Lee JH, Jang JP. Buoyancy-driven heat transfer of water-based $\mathrm{Al}_{2} \mathrm{O}_{3}$ nanofluids in a rectangular cavity. Int J Heat Mass Transfer. 2007;50:4003-4010.

8. Murshed SMS, Nieto de Castro CA. Superior thermal features of carbon nanotubes-based nanofluids - A review, Renew Sust Energy Rev. 2014;37:155-167.

9. Shanbedi M, Heris ZS, Maskooki A. Experimental investigation of stability and thermophysical properties of carbon nanotubes suspension in the presence of different surfactants. J Therm Anal Calorim. 2015;120:1193-201. 
10. Shamaeil M, Firouzi M, Fakhar A. The effects of temperature and volume fraction on the thermal conductivity of functionalized DWCNTs/ethylene glycol nanofluid. J Therm Anal Calorim. 2016;126:1455.

11. Estellé P, Halelfadl S, Maré T. Thermal conductivity of CNT water based nanofluids: Experimental trends and models overview. J Thermal Eng. 2015;1(2):381-390.

12. Halelfadl S, Estellé P, Aladag B, Doner N, Maré T. Viscosity of carbon nanotubes waterbased nanofluids: Influence of concentration and temperature. Int J Thermal Sci. 2013;71:111117.

13. Estellé P. Comment on "Viscosity measurements of multi-walled carbon nanotubes-based high temperature nanofluids". Mat Lett. 2015;138:162-163.

14. Li Y, Suzuki S, Inagaki T, Yamauchi N. Carbon-nanotube nanofluid thermophysical properties and heat transfer by natural convection. J Physics: Conf Series. 2014;557:012051.

15. Esfe MH, Arani AAA, Yan W-M, Ehteram H, Aghaei A, Afrand M. Natural convection in a trapezoidal enclosure filled with carbon nanotube-EG-water nanofluid. Int J Heat Mass Transfer. 2016;92:76-82.

16. Halelfadl S, Adham AM, Mohd-Ghazali N, Maré T, Estellé P, Ahmad R. Optimization of thermal performance and pressure drop of a rectangular microchannel heat sink using aqueous carbon nanotubes based nanofluid. App Thermal Eng. 2014;62/2:492-499.

17. Halelfadl S, Maré T, Estellé P. Efficiency of carbon nanotubes water based nanofluids as coolants. Exp Thermal Fluid Sci. 2014;53:104-110.

18. O’Hanley H, Buangiorno J, McKrell T, Hu LW. Measurement and model validation of nanofluid specific heat capacity with Differential Scanning Calorimetry. Adv Mech Eng. 2012; ID 181079.

19. Khanafer K, Vafai K, Lightstone M. Buoyency-driven heat transfer enhancement in a twodimensional enclosure utilizing nanofluids. Int J Heat Mass Transfer. 2003;46:3639-3653.

20. Deng L, Young RJ, Kinloch IA, Sun R, Zhang G, Noé L, Monthioux M. Coefficient of thermal expansion of carbon nanotubes measured by Raman spectroscopy. Appl Phys Lett. 2014;104:051907.

21. Turan O, Sachdeva A, Chakraborty N, Poole RJ. Laminar natural convection of powerlaw fluids in a square enclosure with differentially heated side walls subjected to constant temperatures. J Non-Newt Fluids Mech. 2011;166:1049-1063.

22. Berkovsky BM, Polevikov VK. Numerical study of problems on high-intensive free convection, in: D.B. Spalding, H. Afgan (Eds.), Heat Transfer and Turbulent Buoyant Convection, Hemisphere, Washington, DC, 1977, pp. 443-455. 


\section{Figure Captions}

Figure 1. Schematic of the considered problem

Figure 2. Influence of surfactant content, temperature difference between hot and cold walls and average temperature of base fluids on the Nusselt number of base fluids in square cavity.

Figure 3. Nusselt number of CNT nanofluids in function of volume fraction, average nanofluid temperature and temperature difference between hot and cold walls

Figure 4. Relative Nusselt number in function of volume fraction and average temperature of CNT nanofluids

\section{Table Captions}

Table 1. Rheological properties of base fluids in function of temperature and SDBS volume fraction.

Table 2. Rheological properties of nanofluids in function of temperature and nanoparticles volume fraction. 


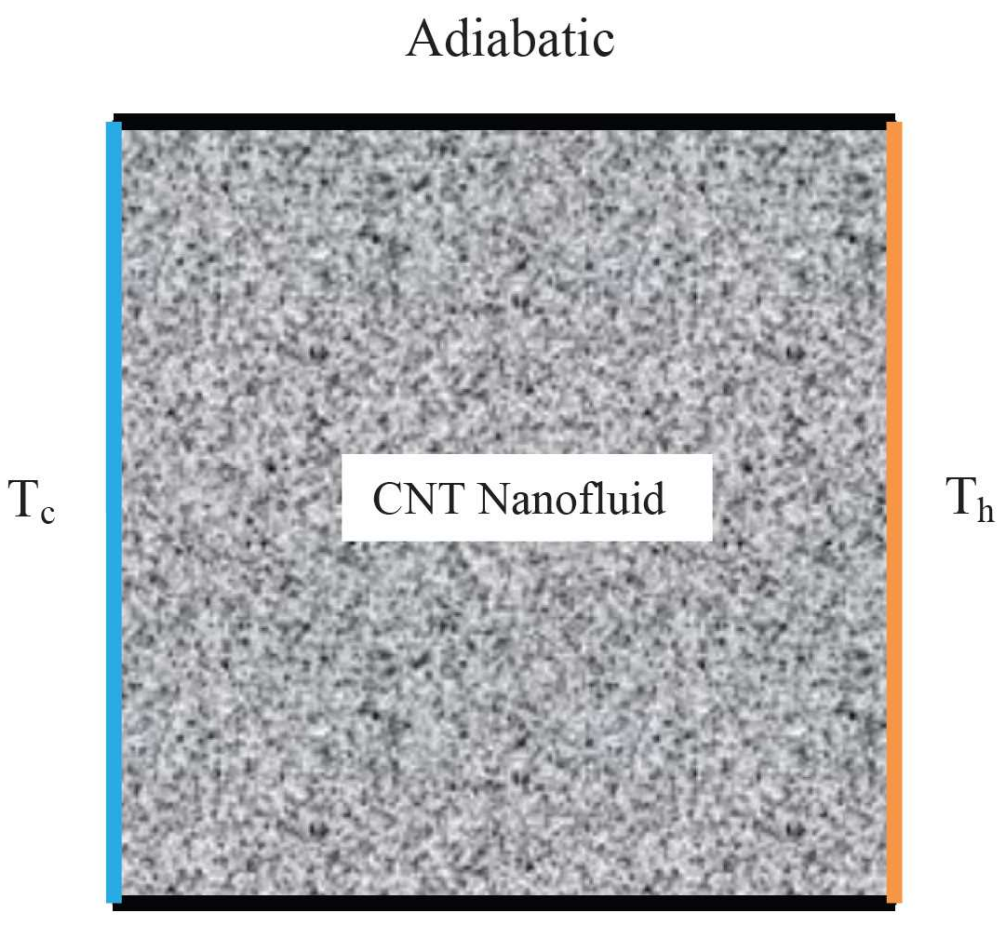

Adiabatic

Figure 1. Schematic of the considered problem 


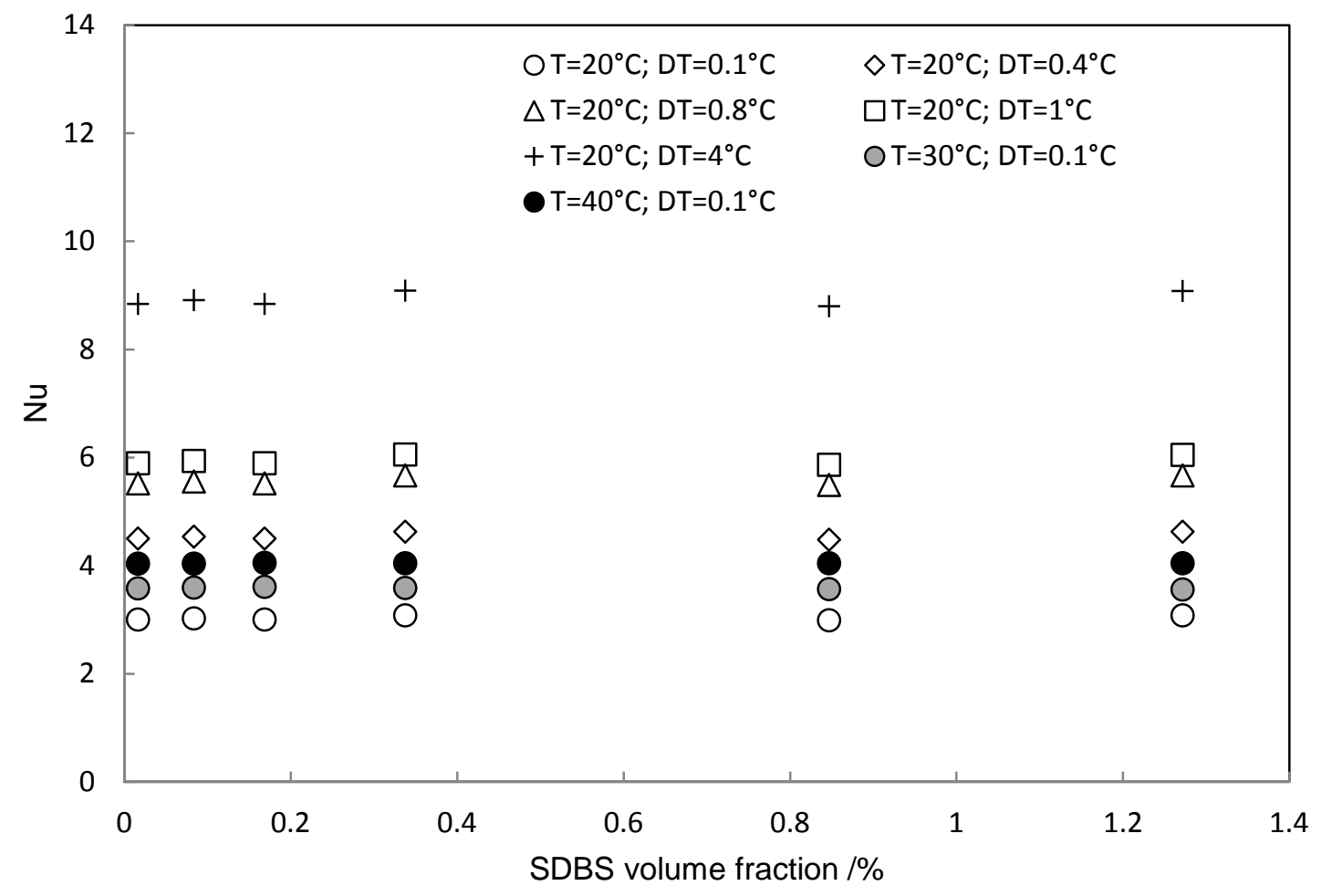

Figure 2. Influence of surfactant content, temperature difference between hot and cold walls and average temperature of base fluids on the Nusselt number of base fluids in square cavity. 


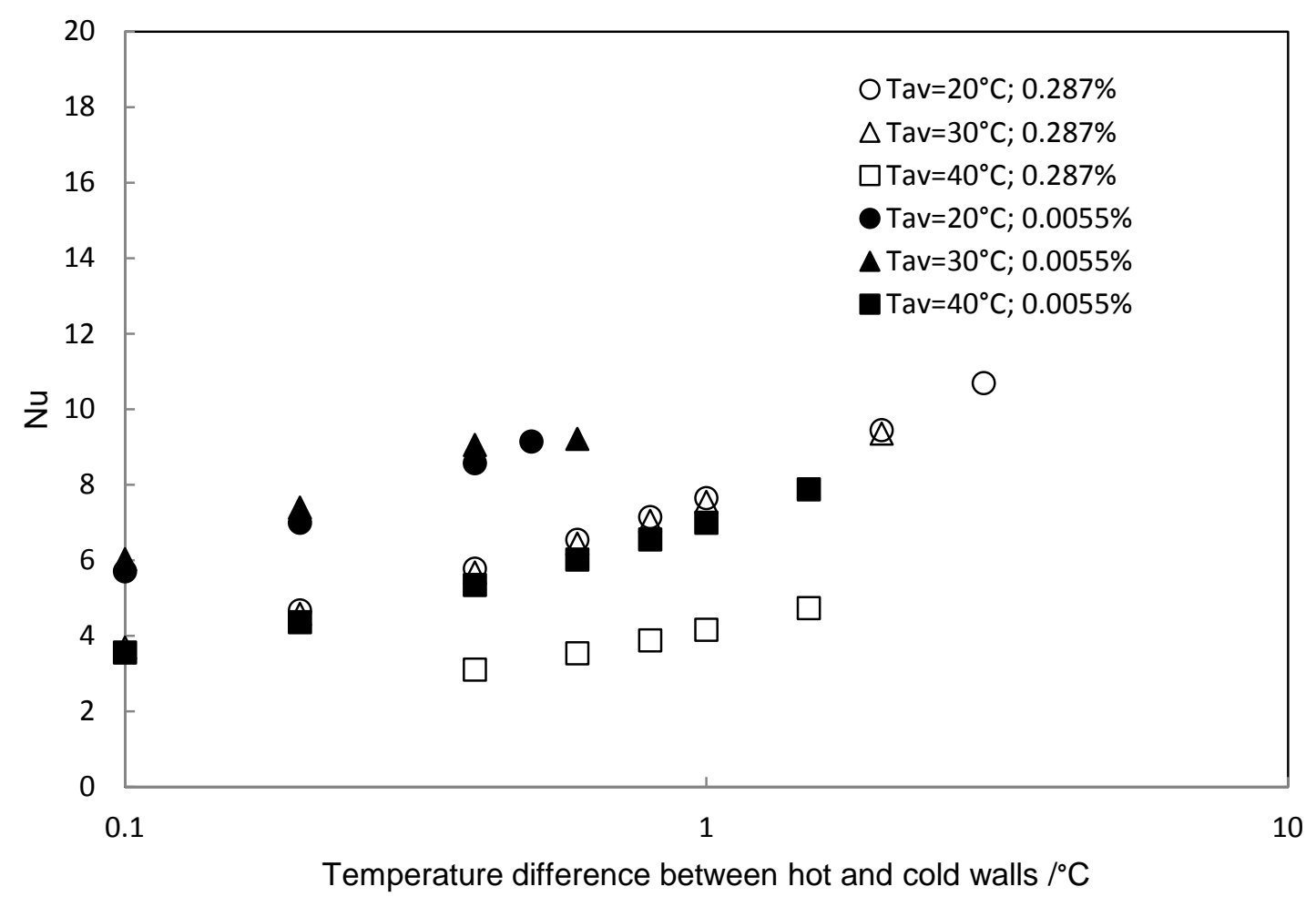

Figure 3. Nusselt number of CNT nanofluids in function of volume fraction, average nanofluid temperature and temperature difference between hot and cold walls 


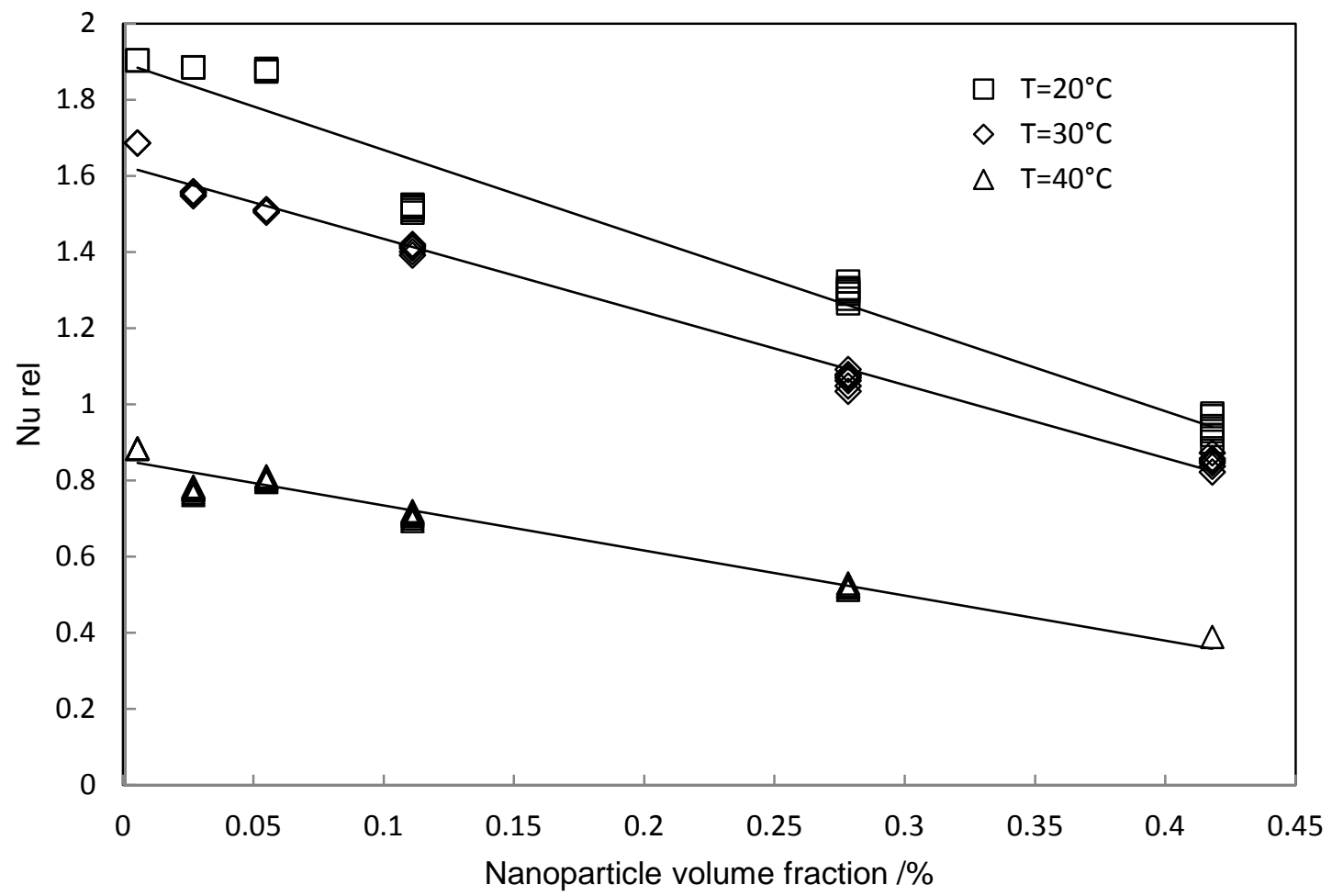

Figure 4. Relative Nusselt number in function of volume fraction and average temperature of CNT nanofluids 
Table 1. Rheological properties of base fluids in function of temperature and SDBS volume fraction.

\begin{tabular}{|c|c|c|c|c|}
\hline \multirow{2}{*}{ Volume fraction (\%) } & \multicolumn{3}{|c|}{ Temperature } \\
\cline { 3 - 5 } & $20\left({ }^{\circ} \mathrm{C}\right)$ & $30\left({ }^{\circ} \mathrm{C}\right)$ & $40\left({ }^{\circ} \mathrm{C}\right)$ \\
\hline $\mathrm{CNT}$ & SDBS & $\begin{array}{c}\mu \\
\mathrm{mPa} . \mathrm{s})\end{array}$ & $\begin{array}{c}\mu \\
(\mathrm{mPa} . \mathrm{s})\end{array}$ & $\begin{array}{c}\mu \\
(\mathrm{mPa} . \mathrm{s})\end{array}$ \\
\hline 0.418 & 1.272 & 1.102 & 0.852 & 0.657 \\
\hline 0.278 & 0.847 & 1.077 & 0.828 & 0.648 \\
\hline 0.111 & 0.338 & 1.046 & 0.799 & 0.637 \\
\hline 0.055 & 0.169 & 1.036 & 0.789 & 0.633 \\
\hline 0.0277 & 0.084 & 1.027 & 0.784 & 0.632 \\
\hline 0.0055 & 0.0169 & 1.026 & 0.780 & 0.630 \\
\hline
\end{tabular}

Table 2. Rheological properties of nanofluids in function of temperature and nanoparticles volume fraction.

\begin{tabular}{|c|c|c|c|c|c|c|c|c|c|}
\hline \multirow{3}{*}{$\begin{array}{l}\text { CNT volume fraction } \\
\qquad(\%)\end{array}$} & \multicolumn{9}{|c|}{ Temperature } \\
\hline & \multicolumn{3}{|c|}{$20\left({ }^{\circ} \mathrm{C}\right)$} & \multicolumn{3}{|c|}{$30\left({ }^{\circ} \mathrm{C}\right)$} & \multicolumn{3}{|c|}{$40\left({ }^{\circ} \mathrm{C}\right)$} \\
\hline & $\begin{array}{c}\mu \\
\text { (mPa.s) }\end{array}$ & $\begin{array}{c}\eta \\
\left(\mathrm{mPa} \cdot \mathrm{s}^{\mathrm{n}}\right)\end{array}$ & $\begin{array}{l}\mathrm{n} \\
(-)\end{array}$ & $\begin{array}{c}\mu \\
(\mathrm{mPa} . \mathrm{s})\end{array}$ & $\begin{array}{c}\eta \\
\left(\mathrm{mPa}_{\mathrm{s}} \mathrm{s}^{\mathrm{n}}\right)\end{array}$ & $\begin{array}{l}\mathrm{n} \\
(-)\end{array}$ & $\begin{array}{c}\mu \\
(\mathrm{mPa} . \mathrm{s})\end{array}$ & $\begin{array}{c}\eta \\
(\mathrm{mPa} \\
\left.\mathrm{s}^{\mathrm{n}}\right)\end{array}$ & $\begin{array}{l}\mathrm{n} \\
(-)\end{array}$ \\
\hline 0.418 & - & 0.008 & 0.859 & - & 0.0058 & 0.866 & - & 0.0059 & 0.826 \\
\hline 0.278 & - & 0.0034 & 0.924 & - & 0.003 & 0.902 & - & 0.0026 & 0.878 \\
\hline 0.111 & - & 0.002 & 0.963 & - & 0.0013 & 0.949 & - & 0.0011 & 0.931 \\
\hline 0.055 & 0.0011 & - & - & - & 0.0011 & 0.983 & - & 0.0008 & 0.964 \\
\hline 0.0277 & 0.0011 & - & - & - & 0.001 & 0.975 & - & 0.0009 & 0.945 \\
\hline 0.0055 & 0.0011 & - & - & 0.000803 & - & - & 0.00066 & - & - \\
\hline
\end{tabular}

